\title{
Some critical considerations about the document Psychotherapies for Anxiety and Depression: benefits and costs
}

\author{
Nino Dazzi \\ Department of Dynamic and Clinical Psychology, Sapienza University of Rome, Italy
}

I would like to make a few considerations to comment on the document we are being presented with, starting from a reflection on its political significance.

There is no doubt that, as a political initiative, even before considering its cultural contents, the document is definitely appreciable, also for the sobriety of its style and the clarity of the message proposed.

While, in recent years, our country has shown great sensitivity towards psychotherapy - it is worth recalling article 3 of the law introducing the Order and Register of Psychologists, 1989, and parliamentary initiatives which, unfortunately, were not concluded - the wording used in the document, which speaks of psychological treatments, certainly appears to be more suitable and in line with the proposals transposed in European and nonEuropean countries (in the United States, as well as in Australia and New Zealand). In Europe, in the wake of the Scandinavian (especially the Swedish) experiences, the English experience is currently underway, which is extremely interesting, though it has elicited critical re-

Correspondence: Nino Dazzi, Department of Dynamic and Clinical Psychology, Sapienza University of Rome, Piazzale Aldo Moro 5 , 00185 Rome, Italy.

E-mail: nino.dazzi@uniroma1.it

Key words: Psychotherapies; Anxiety; Depression; Considerations.

Citation: Dazzi, N. (2017). Some critical considerations about the document Psychotherapies for Anxiety and Depression: benefits and costs. Research in Psychotherapy: Psychopathology, Process and Outcome, 20(2), 156-157. doi: 10.4081/ripppo.2017.281

Received for publication: 23 May 2017.

Accepted for publication: 20 June 2017.

This work is licensed under a Creative Commons Attribution NonCommercial 4.0 License (CC BY-NC 4.0).

CCopyright N. Dazzi, 2017

Licensee PAGEPress, Italy

Research in Psychotherapy:

Psychopathology, Process and Outcome 2017; 20:156-157

doi:10.4081/ripppo.2017.281 actions - disregarding the self-referencing ones of psychotherapeutic approaches that feel threatened.

The social problem of depression and of anxiety disorders is in fact inevitable; likewise undeniable is the favourable cost-benefit ratio and a series of positive effects of validated psychological treatments (consider the 2012 APA Declaration, though it is specifically addressed to psychotherapy; Lilienfeld, Ritschel, Lynn, Cautin, \& Latzman, 2013).

A clear and direct message based on entirely plausible arguments such as this one, can therefore aim to obtain, if not a desirable and definitive success, at least careful attention, and must therefore be unconditionally supported.

Coming now to some strictly scientific considerations, the convincing emphasis - convincing from the political point of view - on the evidence-based approach requires, I believe, an in-depth discussion within the scientific community first, before it takes on, rather than the aspect of a necessary condition, a more general and inaccurate meaning, inasmuch as political and essentially ideological.

The first edition of the volume by Goodheart, Kazdin and Sternberg dates back to 2006 (Goodheart, Kazdin, \& Sternberg, 2006). Since then, research has continued and discussions have expanded. It would suffice to recall the contribution of the Australian Psychological Society, Evidence-based Psychological Interventions in the Treatment of Mental Disorders, though it is not very recent (the third edition came out in 2010), which takes a stand on the issue (and includes in the list of evidence-based treatments also psychodynamic psychotherapy, emotion-focused therapy, family therapy, and family-based interventions, which no doubt raises a problem).

Research on psychotherapies has significantly contributed to ending what has been referred to as a cold war between conflicting directions and approaches. Integrative psychotherapeutic modules are constantly growing and spreading. It would therefore be entirely unacceptable for political stances to steer also the scientific debate, causing the message to be regarded as the proposal of a state therapy. A dangerous message, which would perhaps even have a boomerang effect! 


\section{References}

Goodheart, C.D., Kazdin, A.E., \& Sternberg, R.J. (2006). Evidence-based psychotherapy: where practice and research meet. Washington, DC: American Psychological Association.
Lilienfeld, S.O., Ritschel, L.A., Lynn, S.J., Cautin, R.L., \& Latzman, R.D. (2013). Why many clinical psychologists are resistant to evidence-based practice: root causes and constructive remedies. Clinical Psychological Review, 33, 883-900. 